\title{
Assumption Validation Process for the Assessment of Technology- Enhanced Learning
}

\author{
Denise Pauline-Graf \\ Novomatic AG, Austria \\ University of Phoenix, Phoenix, AZ, USA \\ ORCID: 0000-0001-5295-4488 \\ Susan E. Mandel \\ Lake Health, OH, USA \\ ORCID: 0000-0002-0420-4540 \\ Heather W. Allen \\ SADI Solutions, LLC, MO, USA \\ ORCID: 0000-0002-6680-9764 \\ Lynne E. Devnew \\ College of Doctoral Studies, University of Phoenix, AZ, USA \\ ORCID: 0000-0002-7516-2448
}

Received: 6 Nov 2020

Accepted: 23 May 2021

\begin{abstract}
Technology-enhanced learning (TEL) is a broad term to denote the incorporation of digital technology to mediate activities that support education. Educational researchers need to validate critical assumptions about any new system that involves TEL early and throughout its development course to make quick, informed, de-risked decisions about the progress of TEL. We introduce an assumption validation process for educational researchers to consider utilizing when evolving ideas or prototypes of TEL. We present a preliminary study conducted in Russia of a knowledge sharing (KS) training program using digital games to illustrate the proposed four-stage process. The first stage is listing the assumptions that apply to initiatives of TEL. The second is identifying the methods most useful for testing those assumptions. The third is executing tests on each of those assumptions. The last stage is determining assumption validity. In the illustrative study, a single pilot trial was considered the appropriate approach to validate the assumptions selected in the first stage. We found that determining assumption validity requires testing many of the assumptions individually and in aggregate. Educational researchers can use this assumption validation process to assess the potential of TEL in a variety of settings before investing resources into its further development.
\end{abstract}

Keywords: instructional digital games, assumption validation, knowledge sharing, pilot trial, self-efficacy, technology-enhanced learning

\section{INTRODUCTION}

Technology-enhanced learning (TEL) is a broad term (Bayne, 2015; Kurvinen et al., 2020) to denote the incorporation of digital technology to mediate activities that support education (Goodyear \& Retalis, 2010). In the developed, 21st-century economy, instructional activities involve some components of TEL and are 
expanding in non-formal, higher, and vocational education in Russia (Filippova, 2015; Larionova et al., 2018) and in education across the globe (Sanders, 2012). An example within the context of TEL is digital game-based learning. This teaching approach involves the use of computer games that enable learners to engage in content to enhance the learning experience of a discrete skill or a particular learning outcome (Oliver, 2018; Tang et al., 2013). The need to expand content to fulfill modern educational purposes confronting the digital age challenges (Vetushinskiy \& Zhukov, 2019) plays a significant role in the spread and advancement of digital game-based learning. Digital game-based learning offers educators the opportunity to provide other teaching methods necessary for learners born and raised in a digital environment (Liu et al., 2020).

Russia and the world are starting to emphasize incorporating values of teamwork and collaboration in their instructional systems that must fulfill criteria of personalization, soft skill development, and real-life relevance (Apiola et al., 2019; Vetushinskiy \& Zhukov, 2019). The general problem is that the diffusion of technology into teaching and learning has not always lived up to its transformative promise of successful implementation and application (Niederhauser et al., 2018). TEL encompasses a complex system of technological, educational, and social change (Bayne, 2015) - for TEL to become an integral part of education, educational researchers must demonstrate the effectiveness, acceptability, and feasibility of the system's outcome measures. As such, the appraisal of TEL as part of educational practice is crucial if underdeveloped.

The specific problem is ongoing challenges lie in the appraisal of TEL both in literature and in practice. Authors have reported studies on the replication and supplementation of instruction with technology (Kirkwood \& Price, 2014); the practical use of technology, including the types of activities learners found most useful; learners' attitudes toward specific technological programs; the benefits and downsides of technology on the educational experience (Kirkwood \& Price, 2013); and design issues in technology creation (Bennett \& Oliver, 2011). Even though institutions promote the integration and the effective use of technology in education, educational researchers have not fully realized its transformational effect (Crook \& Gu, 2019). Internal and external barriers can exist to technology introduced to instruction (Filippova, 2015; Larionova et al., 2018) including psychological, methodological, and organizational challenges. Low confidence levels by teachers and learners can exacerbate apprehension toward using novel models of instruction and new technology. Unsuitable pedagogy (the theory and practice of teaching, learning, and assessment), inadequate understanding of personalized instruction, poor strategic implementation of TEL, and lack of organizational support for learners' engagement in TEL can impede education with technology.

While reported studies on TEL provide valuable information on the motive for using technology in education, they exclude an emphasis on the how (Kirkwood \& Price, 2014; Passey, 2019). In a systematic review of literature on learning personalization, Bartolomé et al. (2018) discovered that environments and experiences involving educational technology are devoid of an explicit educational foundation or pedagogy and questioned the significance of pedagogical assumptions underlying education models and action. A need, therefore, exists to validate critical assumptions about TEL early and often in its course of development and implementation to make quick, informed de-risked decisions about its progress for the following reasons:

1. The development and implementation of TEL are costly. Institutions invest financially in the equipment's implementation, including employing infrastructure technicians to deliver the technological support that aids in the successful utilization of the technology. The technology's use for teaching and learning also demands personal investment from staff and learners (Kirkwood \& Price, 2014). Addressing the concerns of these stakeholders necessitates the appraisal of efforts pertaining to TEL.

2. Educational researchers may overlook aspects of TEL in mainstream appraisal practice, for example, the learning environment, acceptability, and feasibility of education using technology that plays an essential part in the assessment of TEL.

3. The teacher-learner interactions in TEL differ from the teacher-learner interactions in conventional learning modalities not mediated by technology. Traditional learning modalities do not generate the same informal appraisal opportunities as those generated by nonconventional modalities (Cook \& Ellaway, 
2015). As a result, TEL may require a more thorough assessment approach than other instructional activities.

4. Approaches to TEL yield more and a greater variety of data than conventional instructional approaches. "Big data" (Ellaway et al., 2014a, p. 216) analytics for educational development require novel approaches that conceptually and procedurally support appraisals (Ellaway et al., 2014a).

5. Educational researchers must be precise in what they evaluate to pursue lines of inquiry that end in enlightenment. Theory and practice of TEL include assessments of the instructional technology itself and assessments of the use of instructional technology in differing contexts (Ellaway et al., 2014b, March 9). Clear distinctions are necessary among the assessment of TEL as a technology (e.g., the reliability, sustainability, and alignment of the technology to the environment), as educational content (accuracy and in adherence to current, effective education principles), and as part of an overarching learning activity (the achievement of objectives and outcomes) (Ellaway, 2014).

Appraisals of TEL are not neutral or value-free. They are a reflection of the assumptions that shape the inquiries that researchers undertake (Kirkwood \& Price, 2013), influencing the scope of studies and the outcomes of TEL. However, challenges lie in the failure to reveal the assumptions and limitations that underpin assessments of TEL and thus in the ability to question the extent to which educational researchers support conclusions with evidence using the appropriate preliminary study.

The objective of this paper is to introduce an assumption validation process for educational researchers to consider utilizing when evolving ideas or prototypes of TEL to address the question, "How can educational researchers identify, reveal, and validate critical assumptions about TEL early and often in its course of development and implementation to make quick, informed de-risked decisions about its progress?" Further, the limitations of the assumption validation process are addressed.

Although models and frameworks exist to support the appraisal of TEL (Cook \& Ellaway, 2015; Pickering et al., 2019), no studies have been reported on a process that helps educational researchers identify and make explicit their assumptions. An assumption validation process for TEL assessment is developed so that educational researchers can confidently predict that their critical assumptions are neither false nor go unnoticed. The process is illustrated by presenting a preliminary study of a knowledge sharing (KS) training program with digital games, conducted in a Russian subsidiary of a global gaming technology company. A full-scale study was planned to follow the preliminary study in the company's headquarters in Austria to prevent the duplicate enrollment of participants in the study. The preliminary study's research question was, "What is the difference, if any, in mean pre- and post-individual and team behavior in KS between participants who played Digital Game Version Self-Efficacy (DGVSE) and participants who played Digital Game Version Non-Self-Efficacy (DGVNSE) at 275 minutes?" The acceptability and feasibility of the outcome measures of the TEL intervention were also evaluated. The digital game versions were equal in terms of playable in-game characters that drove the storyline and duration of the game experience; however, one version contained self-efficacy components for teamwork that required players in the intervention group to depend on each other to complete in-game team tasks, and the other did not. In the alternate version of the digital game played by the control group, teamwork self-efficacy components were removed or 'switched off.' An example of the ten teamwork self-efficacy components in the game required players to depend on each other to set time deadlines for task achievement. An example of a behavior a player could decide to practice in KS is trust.

\section{CONCEPTUAL MODEL OF TEL}

\section{Models and Frameworks of TEL}

Educational researchers have designed models and frameworks to support the appraisal of TEL in medical education. Whereas, Cook and Ellaway (2015) outlined a three-step evaluation model that links utility (stakeholders' needs and guiding questions), principles (approaches to inquiry), and practice (specific data collection activities and instruments), Pickering et al.'s (2019) framework of TEL consists of four levels. The 

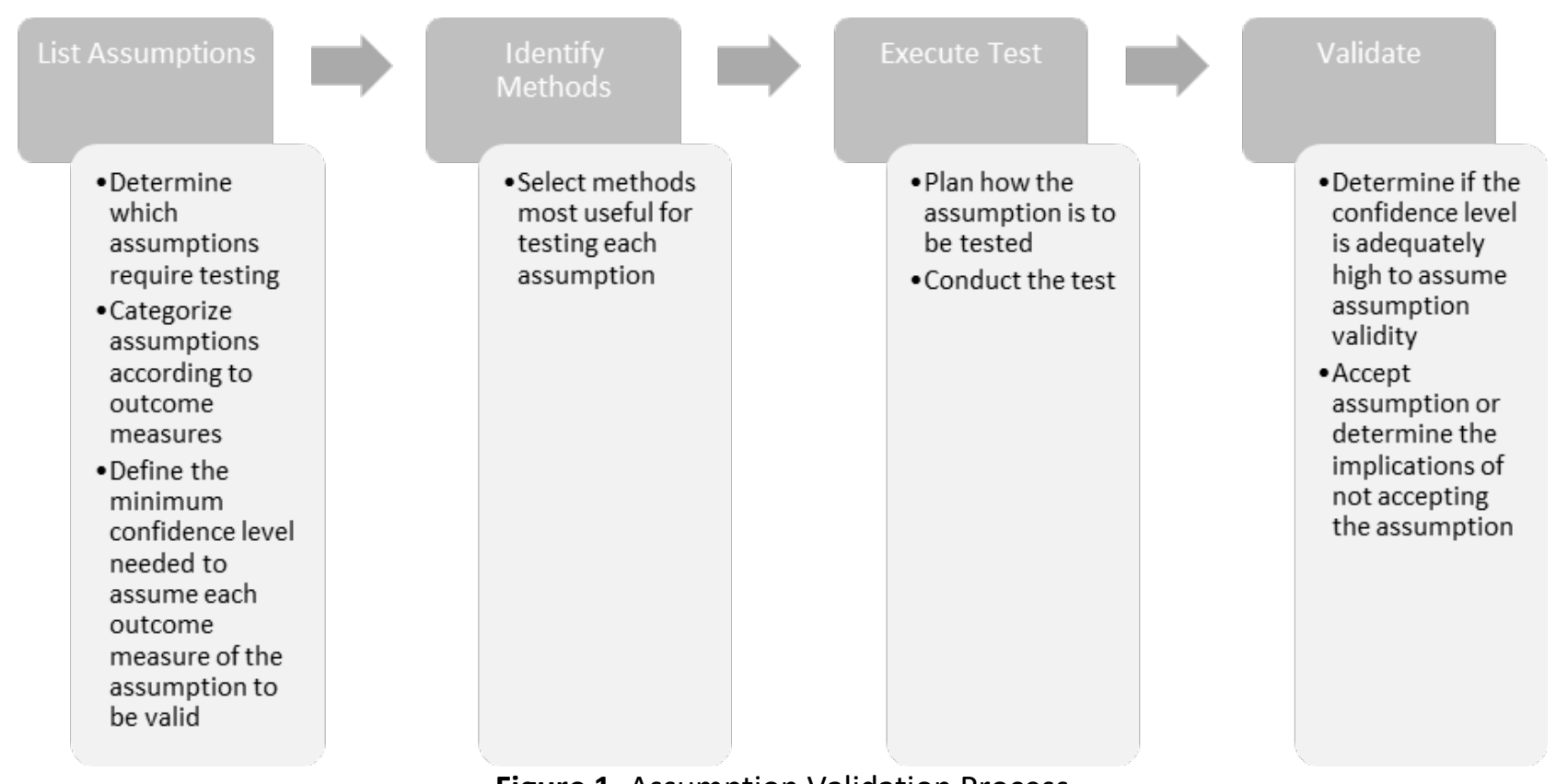

Figure 1. Assumption Validation Process

first level includes a focus on the assessment of the rationale for introducing TEL. The second and third levels include a focus on learners' satisfaction with the technology, the underlying effect on learners' gains, and a comparison of the influence of TEL on learners' outcomes versus other available learning approaches. The fourth and most complex level of the Pickering et al. (2019) model involves drawing on learners' and numerous stakeholders' input to judge the institutional benchmarks used in assessing the success of TEL in terms of value for money. These appraisal models and frameworks are not inherently good or bad, but concern remains on how researchers appraise TEL (Cook \& Ellaway, 2015; Kirkwood \& Price, 2013, 2014; Passey, 2019).

\section{The Assumption Validation Process Model of TEL}

The proposed assumption validation process is a portion of the development of the TEL's assessment process and is divided into four stages, with each stage consisting of several steps (see Figure 1). It is recommended that assumption categorization in the first stage be divided into primary and secondary outcome measures that fulfill the intended purpose of TEL. Following the first stage of the assumption validation process, educational researchers would select the preliminary research methods most useful for testing each assumption.

Various types of preliminary studies have different characteristics related to definition, objectives, and methodology (Pauline-Graf \& Mandel, 2019). In conjunction with the model of the assumption validation process, educational researchers are advised to use the appropriate preliminary study to address issues to be learned from such a study before investing resources in a full-scale study. For example, the objective of pilot work that involves identifying features or conditions of a study differs from those of a feasibility study to assess a study's viability, or a pilot trial with the purpose of testing aspects of a quantitative study in preparation for a full-scale study assessment (Pauline-Graf \& Mandel, 2019).

The participants, the research context, and the description and instrumentation of TEL are integral to the test execution or third stage of the assumption validation process. The last stage involves reviewing the results of the outcome measures defined in the first stage. Educational researchers can determine from test findings whether to continue with the assumptions underlying the development and implementation of TEL. 


\section{LITERATURE REVIEW}

\section{Assumptions of TEL}

Assumptions about TEL can be defined as presuppositions about teaching and learning via technology advancements. Even though researchers may take interpretations about teaching and learning for granted (Kirkwood \& Price, 2013), divergent conceptions of instruction exist (Samuelowicz \& Bain, 1992). Whereas some educators possess teaching-centered conceptions (Prosser et al., 1994) (i.e., instruction as the transference of information, skills, and attitudes to learners), others possess learning-centered conceptions (i.e., instruction as the development of learners' conceptual understanding) (Swinkels et al., 2013). Kirkwood and Price (2013) noted that educators consider whether the educator or the technology is significant. Educators' conceptions of instruction are a reflection of attitudes about the agency and influence how educators employ technology, affect learners' learning, and conduct research and interpret findings.

\section{Appraisals of TEL}

The outcomes of studies of emerging technologies are not a demonstration of the technology's improvement of student learning (Kirkwood \& Price, 2013) although it may be implied that TEL must improve education in terms of quality, value, or extent (Kirkwood \& Price, 2014). TEL requires a comprehensive understanding of the prerequisites of education: pedagogy and the emanating trends in research (Passey, 2019). The processes followed for TEL appraisals are often undefined or vague and affect the outcomes researchers profess to have discovered (Oliver, 2011). Issues involve the improper use of theoretical foundations in research studies on TEL (Passey, 2019), ill-defined purposes of assessments of TEL, obscure associations between what evaluators assessed and what transpired, the lack of robust conceptual groundings for TEL, and the inadequacy of sound assessment methods (Cook \& Ellaway, 2015).

The absence of conclusive findings is apparent in appraisals of TEL (Kirkwood \& Price, 2013; Pickering et al., 2019). Researchers may exclude or downplay the assumptions associated with TEL as they pertain to its effectiveness (Kirkwood \& Price, 2013; Passey, 2019). This lack of clarity about theoretical assumptions could result from institutions and organizations directing funds to equipment rather than pedagogy (Passey, 2019). As a result, educational researchers may view theory and empirical work as separate entities, raising concern for the researchers' use of appropriate assumption-based planning when defining the processes involved in enabling pedagogical innovation with technology.

\section{Digital Game-Based Learning Appraisals}

Within the context of TEL, the implementation of digital games in teaching can motivate learners to be active participants in the process of meaningful learning (Shahriarpour \& Kafi, 2014). Digital games contribute to experiential learning and complement conventional educational methods typically reliant on observational learning such as lectures or training videos (Lee, 2015). The experiential learning process includes an emphasis on self-development, the usefulness of challenging and motivating experiences for learning (Courtright et al., 2014), and feedback (Kiili, 2005) to improve and maintain learners' cognitive engagement (Gresalfi \& Barnes, 2016).

Evident from emerging discourses on digital games for learning, a distinction exists between game-based learning and gamification. Gamification does not compulsorily entail a computer. It is a process or training in the form of a game (Liu et al., 2020) that involves the use of game esthetics, mechanics, and logic to engage and encourage learners to find solutions to problems (Cózar-Gutiérrez \& Sáez-López, 2016).

Researchers devoted to digital game-based learning evaluations have revealed significant increases in learners' attraction to and engagement in games as well as learners' motivation to learn with games (Hussein et al., 2019; Hwa, 2018; Khan et al., 2017). Simultaneously, many researchers have proved the negative influence of digital games' use on learners' motivation to learn, emotional state and cognitive abilities (Giannakas et al., 2018; Qian \& Clark, 2016). However, in this technology-driven society, there may be no alternative to digital games' use in teaching because of a transformation in the perception of the 
environment among generations of learners who are accustomed to entertainment that encompasses digital graphics in most spheres of life such as film, television, and advertising (Al-Azawi et al., 2016).

Although the appraisal of TEL is the process of determining the value of applying technology to education and possesses theoretical dimensions, it is largely a practical endeavor. Assessors need to understand what they will appraise, how they will conduct the appraisal, what assumptions underlie their methods, and how they will report and use the assessment findings (Frye \& Hemmer, 2012). To this end, value exists in the incremental adaptation of technology to support a pedagogical approach by introducing a process for educational researchers to validate their specific assumptions about TEL, crucial to making quick, informed, de-risked decisions about the progress of TEL throughout its course of development and implementation.

\section{METHODOLOGY}

To illustrate the proposed assumption validation process, a preliminary study of a specific application of TEL - a KS training program using digital games-is provided. The training program involved activities related to the teaching and learning of KS in organizations. The utilization of an assumption validation process would improve the quality of assessments of the progress of TEL and would require attention to appropriate statistical tests, validated measurement tools, learning objectives, learner-related variables, learning context, available resources, and consideration of additional dynamic elements that improve learners' educational experience including learners' perceptions and behavior. Educators as designers of TEL should consider the design process as a cyclical process of refinement (Persico et al., 2018) rather than a one-step process. The assumption validation process is a critical and potentially recurring step in the TEL's development process, and it is advisable to commence with the first prototype (see Figure 1).

Each stage of the proposed four-stage assumption validation process is illustrated by presenting a preliminary study of a KS training program with digital games.

\section{KS Training Program}

The KS training program is an illustrative example of applying the assumption validation process, a four-stage process. The first stage is listing the assumptions that apply to initiatives of TEL. The second is identifying the methods most useful for testing those assumptions. The third is executing tests on each of those assumptions. The last stage is determining assumption validity.

\section{Sample description of TEL}

The theory behind and embedded in this initiative of TEL, specifically designed to enhance KS in a Russian subsidiary of a casino gaming manufacturing company, is briefly reviewed before introducing each step of the assumption validation process. Games can afford learners the freedom to model or display KS-related behaviors because they offer simulated environments where learners can safely test themselves without the concern for failure, attempt alternate solutions, and acquire new behaviors in the process. Safe environments help to promote tacit KS among people (Van Genderen, 2014). KS gives an organization a competitive edge (Olowodunoye, 2015); however, KS is an unspontaneous act that requires motivation (Shaari et al., 2014). Even within an organization, KS might occur within some groups or among some individuals. It requires a change in people's attitudes toward receiving and giving knowledge (Ojedokun \& Idemudia, 2014).

Self-efficacy, defined as "belief in one's capabilities to mobilize the motivation, cognitive resources, and courses of action needed to meet a given situational demand" (Bandura, 1977, p. 408), is a cognitive factor that facilitates KS (Shao et al., 2015). Transcending self-efficacy for teamwork, team efficacy is a crucial analogue based on the notion that self-efficacy is aggregated from the individual level to the team level (Chen \& Lin, 2013). Team efficacy is a shared belief among team members that their team can achieve tasks such as coordination or KS (Chen \& Lin, 2013). Learners can require a sense of efficacy for teamwork to believe that sharing knowledge is achievable with their skills. Team behavior entails viewing the team as though it functions as a unit in which members contribute to the collective pool of behavior in that team (Tasa et al., 2007). A team behavior, such as KS, does not imply that each team member contributes the same amount of 
KS within the team; instead, individuals in a team tend to adopt KS behaviors through direct observation and assessment of other people's KS capabilities in that team. The average behavior in KS for that team subsequently increases or decreases (Tasa et al., 2007). Increases in self-efficacy are possible using appropriate instruction and learning strategies (Hagemeier et al., 2014; Zawadzki et al., 2012). The potential for digital games to provide interactive opportunities for exploratory learning activities in a fun way (Li et al., 2013) can offer a promising approach to the repositioning of learners' self-efficacy, teamwork efficacy, and team efficacy beliefs. Game-like systems can give the learners an embodied challenge experience to reflect on the learning task ( $\mathrm{Li}$ et al., 2013). Learners can analyze the game's virtual environment; develop a hypothesis based on the in-game challenge and take action. Learners, in this illustrative case, develop their self-efficacy regarding KS within the virtual world.

The development of TEL is a complex, context- and person-dependent process (Van Driel \& Berry, 2012). A potential solution to the challenge of the appraisal of TEL is the use of an appraisal "recipe" (Harvey, 1998, p. 8) - a brief guideline of a process to address a particular audience and need (Cook \& Ellaway, 2015). We illustrate the application of TEL to assess the KS of participants of a training program with digital games and offer a description of how educational researchers can use the assumption validation process for quick, derisked, informed decision-making in the appraisal of TEL. Although we use the term program to refer to the instruction unit under evaluation, educational researchers can equally apply the assumption validation process to courses or modules that incorporate TEL.

\section{List Assumptions}

Three critical assumptions that required testing were listed about the KS training program, and each of these assumptions was based on the validity of a large number of additional assumptions:

- KS training program is effective.

- KS training program is feasible.

- KS training program is acceptable.

\section{Assumptions underlying effectiveness}

Although the assumptions underlying the training program's effectiveness in terms of KS were not identified before conducting the illustrative pilot trial, the first critical assumption was that the digital game specifically designed to improve KS was likely to improve KS in individual team members and in the team itself. We categorized individual KS and team KS as the training program's primary outcome measures. The assumption underlying the training program's effectiveness was based on self-efficacy, team efficacy, and KS theory. The assumption related to effectiveness was:

A person's self-efficacy for teamwork is likely to increase team efficacy, and an increase in team efficacy is likely to increase individual team member's self-efficacy regarding KS in teamwork and team members' engagement in KS.

\section{Assumptions underlying feasibility}

Feasibility of the training program's outcome measures included assumptions on delivery, which concerned the administration of the digital games, including the number of hours necessary to deploy the application, set up the server, and run tests in preparation for the participants to play the digital games. Assumptions related to feasibility also included time, which was defined as the additional training support needed during 275 minutes of the training regimens. Costs were a further assumption related to the feasibility of the outcome measures and included the financial implication of offering the KS training program using a digital game compared to manual training, such as face-to-face training.

The assumptions related to feasibility were:

- Delivery of the application to users would be no more than $5 \mathrm{hr}$. 
- The time for additional trainee support would be no more than 60 requests.

- The cost of offering the KS training program, including initial development and delivery costs, would be no more than US\$150,000.

\section{Assumptions underlying acceptability}

Assumptions related to the acceptability of the training program's outcome measures included assumptions on the recruitment rate and participant dropout rate. The recruitment rate was calculated as the proportion of those contacted who consented to participate in the training. The dropout rate was recorded as those chosen and accepted to participate but failed to complete the training. The number of participants who consented and remained in the training and participants' comments on the instructional and entertaining elements of the KS training program indicated whether the participants experienced the training as acceptable.

The assumptions related to acceptability were:

- Greater than $79 \%$ of the recruited participants partook in the training program.

- Less than $5 \%$ of the participants dropped out.

\section{Identify Methods}

Having determined what assumptions would be tested to establish the validity of the training program's outcome measures for effectiveness, feasibility, and acceptability, it was determined they could all be validated in a single pilot trial to be conducted within the organization at a manufacturing subsidiary in Russia.

\section{Study design}

Pilot trials are planned, small-scale preliminary studies (Pauline-Graf \& Mandel, 2019) that serve an important role in determining outcomes of TEL. Pilot trials are stand-alone pilot studies with a randomization procedure (Arnold et al., 2009) designed to obtain and evaluate primary outcome measures (effectiveness) and secondary outcome measures (feasibility and acceptability) in preparation for a full-scale study assessment (Pauline-Graf \& Mandel, 2019). The preliminary study, which was presented as an example of testing the assumption validation process, was a pilot trial.

\section{Sample, setting, and random assignment}

The sample size requirement was based on the feasibility and precision of estimates that involve a betweengroup effect size. The effect size, $d$, was estimated at 0.43, a moderate effect size (Beckstead, 2013). Similarly, a power calculation indicated a sample size of at least 57 participants to determine a significant effect of the KS training program. Thirty participants in each group were required to provide $80 \%$ power at the $5 \%$ significance level to detect effects of 0.43 , a moderate effect size derived from averaging the effect sizes in Koh and colleagues' (2010) study that involved game-based learning on student motivation and performance.

One-hundred-and-forty-three participants were eligible to take part in the pilot trial. Inclusion criteria were participants, 18-64 years old, who worked in a casino manufacturing company in Russia and were willing to provide written informed consent before participating in the KS training program. A convenience sample of sixty-three participants from the target population of 143, all of whom were invited to participate in the study by email, consented to participate in the study. Baseline demographics, including age and gender, were collected via the informed consent form. Three of the consenting participants were randomly selected for exclusion from the study because of a lack of ample tablet computers and training space for more than sixty participants.

Sixty participants ( $42 \%$ of the population) gave signed informed consent and were randomly assigned to three-person teams. The teams were randomly assigned to groups to serve in one of two conditions using a computer program: playing DGVSE (Group 1) or playing DGVNSE (Group 2). Each group, therefore, consisted 
of ten teams of three. This dual-layer of random assignment, achieved using a computer program, controlled for sources of systematic variation or variation because of non-uniformity in each condition.

\section{Sample, setting, and random assignment}

The sample size requirement was based on the feasibility and precision of estimates that involve a betweengroup effect size. The effect size, $d$, was estimated at 0.43, a moderate effect size (Beckstead, 2013). Similarly, a power calculation indicated a sample size of at least 57 participants to determine a significant effect of the KS training program. Thirty participants in each group were required to provide $80 \%$ power at the $5 \%$ significance level to detect effects of 0.43 , a moderate effect size derived from averaging the effect sizes in Koh and colleagues' (2010) study that involved game-based learning on student motivation and performance.

One-hundred-and-forty-three participants were eligible to take part in the pilot trial. Inclusion criteria were participants, 18-64 years old, who worked in a casino manufacturing company in Russia and were willing to provide written informed consent before participating in the KS training program. A convenience sample of sixty-three participants from the target population of 143, all of whom were invited to participate in the study by email, consented to participate in the study. Baseline demographics, including age and gender, were collected via the informed consent form. Three of the consenting participants were randomly selected for exclusion from the study because of a lack of ample tablet computers and training space for more than sixty participants.

Sixty participants ( $42 \%$ of the population) gave signed informed consent and were randomly assigned to three-person teams. The teams were randomly assigned to groups to serve in one of two conditions using a computer program: playing DGVSE (Group 1) or playing DGVNSE (Group 2). Each group, therefore, consisted of ten teams of three. This dual-layer of random assignment, achieved using a computer program, controlled for sources of systematic variation or variation because of non-uniformity in each condition.

\section{Procedures: game administration}

A research team provided the game instructions and administered a game version playable on tablet computers to each group. Each three-person team played for 55 minutes each day over five consecutive days (275 minutes of gameplay per player) from Monday through Friday. The research team briefed participants about the study's purpose, and provided a short description of the game's three player characters (PCs) and the game's goal. The goal was for team players to understand the game's challenges, the source of resistance to game change efforts, and the importance of communication among each other to adapt quickly to change in the game environment by discarding strategies less favorable for productivity compared to others. Trainers instructed the participants not to reveal or discuss the game with each other after each training day to reduce confirmation bias or people's inclination to seek information to support pre-existing beliefs (Baack et al., 2015). After the first training day, game-related discussion among participants was reduced by starting the experimental group 15 minutes earlier than the control group. See Appendix A for the game's description.

\section{Execute Test}

\section{Measurement}

Between-group differences in KS were measured before and after playing a digital game using the Behaviour (sic) in the Knowledge Sharing questionnaire (Osman et al., 2015). The questionnaire is a 3-point Likert-type instrument that allowed participants to self-report their experiences concerning their behaviors in KS. A positive, neutral, or negative response to each item was allocated a value of 2,1 , or 0 , respectively. The questionnaire items relate to three essential factors that underlie behavior in KS and include trust, reciprocal relationships, and a favorable atmosphere (Osman et al., 2015). The measurement tool elicits a selfevaluation of a person's behavior in KS. Trust is the readiness of a team member to accept and transfer knowledge to others and positively relates to KS (Osman et al., 2015). Associations among team members that involve the cooperative interchange of privileges such as knowledge exchange are reciprocal relationships and can create a favorable attitude toward KS. A favorable atmosphere is a positive environment that involves a balanced approach to acquiring and transferring knowledge, neither misusing nor misapplying it. 
Table 1. In-group differences in the primary outcome, behavior in KS for individuals and teams

\begin{tabular}{lcccccc}
\hline Outcome measure & \multicolumn{3}{c}{$\begin{array}{c}\text { Experimental Group } \\
\text { (mean (SD)), } \mathrm{n}=30\end{array}$} & \multicolumn{3}{c}{$\begin{array}{c}\text { Control Group } \\
\text { (mean (SD)), } \mathrm{n}=30\end{array}$} \\
\hline & Pre-test & Post-test & Change & Pre-test & Post-test & Change \\
\hline Individual Behavior in KS & $23.37(3.03)$ & $23.63(3.26)$ & $-.27(2.21)$ & $22.80(2.75)$ & $21.73(5.00)$ & $1.07(4.53)$ \\
Team Behavior in KS & $23.37(2.12)$ & $23.63(2.03)$ & $-.27(1.31)$ & $22.80(1.20)$ & $21.73(2.42)$ & $1.07(1.99)$ \\
\hline
\end{tabular}

\section{Data analysis}

The paired sample t-test using pre- and post-test individual KS scores was performed to validate the assumption of effectiveness. Individual KS was calculated by summing the responses on each of the items of the KS questionnaire. The assumption of normality scores in each group was evaluated using the ShapiroWilk test, appropriate for small sample sizes. The Shapiro-Wilk test for the experimental group post-test $(n=30, p=.0030)$ and the control group post-test $(n=30, p=.0001)$ was found tenable.

The test to validate the feasibility assumption of delivery included measuring the number of hours the developer needed to set up the server and run tests so that the games were ready for use. The test to evaluate the feasibility assumption of time was evaluated by asking participants whether they needed additional support during the training program. The test to validate the feasibility assumption of the cost to deliver the program involved identifying and calculating the fixed costs, participants' costs, and variable costs. Fixed costs included costs for software, hardware, training program design, and production. Participants' opportunity costs included average salary costs for participants. The fixed and variable costs for the training method were computed according to the costs for training, including the welcome introduction and the fiveday training course, which involved participants playing a digital game in their teams. The financial implication of offering the training was compared to a manual training method, face-to-face action learning per participant.

The test to validate the acceptability assumption of the recruitment rate involved computing the proportion of those contacted with the number of participants who consented to participate in the training. The dropout rate was recorded as those chosen and accepted to participate who failed to complete the training. The number of participants who consented to participate, the number who remained in the training, and the participants' comments on the training program's instructional and fun aspects were an indication of whether participants experienced the program as acceptable.

\section{Validate}

In this stage, educational researchers must accept their assumptions or determine the implications of not accepting the assumption. Evident from the positive mean change for the experimental group, the KS behavior of participants was .27 greater (on average) after the training program. Evident from the negative mean change for the control group, KS behavior for the control group was 1.07 less (on average) after the training program. Table 1 includes a summary of in-group differences in the primary outcome behavior in KS for individuals and teams after they played a digital game for 55 minutes during each of five consecutive days (from Monday to Friday).

The Shapiro-Wilk test for the experimental group post-test $(n=30, p=.0030)$ and the control group post-test $(n=30, p=.0001$ ) was statistically significant, indicating data were not normally distributed, which calls into question the validity of the assumption related to effectiveness and its findings.

Apparent from the results of the independent t-test, the difference in individual behavior post-test between the experimental group that played DGVSE $(M=23.63, S D=3.26)$ and the control group that played DGVNSE $(M=21.73, S D=5.00)$ was not statistically significant, $t(58)=-1.744, p=.086, d=.45 .(p>.05)$. Therefore, there was insufficient evidence to reject the null hypothesis that there is no difference in pre- and postindividual behavior in KS between team members who play DGVSE and team members who play DGVNSE at 275 minutes. The between-group effect size post-test, $d=.45$ was moderate. The $95 \%$ confidence interval for the difference in means ranged from -4.081 to .289 . 
Table 2. Independent samples t-test to show mean differences in post-test individual behavior in KS between the experimental group and control group

\begin{tabular}{|c|c|c|c|c|c|c|c|c|c|c|}
\hline & & \multicolumn{2}{|c|}{$\begin{array}{l}\text { Levene's Test } \\
\text { for Equality of } \\
\text { Variances }\end{array}$} & \multicolumn{7}{|c|}{ T-test for Equality of Means } \\
\hline & & $F$ & Sig. & $t$ & $d f$ & $\begin{array}{l}\text { Sig. (2- } \\
\text { tailed) }\end{array}$ & $\begin{array}{c}\text { Mean } \\
\text { Difference }\end{array}$ & $\begin{array}{l}\text { Std. Error } \\
\text { Difference }\end{array}$ & $\begin{array}{r}95 \% \text { Co } \\
\text { Interval o }\end{array}$ & $\begin{array}{l}\text { idence } \\
\text { he Mean }\end{array}$ \\
\hline & & & & & & & & & Lower & Upper \\
\hline \multirow{2}{*}{$\begin{array}{l}\text { Individual } \\
\text { Behavior } \\
\text { in KS Post- } \\
\text { test }\end{array}$} & $\begin{array}{l}\text { Equal variances } \\
\text { assumed }\end{array}$ & .740 & .393 & -1.744 & 58 & .086 & -1.900 & 1.090 & -4.081 & .281 \\
\hline & $\begin{array}{l}\text { Equal variances } \\
\text { not assumed }\end{array}$ & & & -1.744 & 49.941 & .087 & -1.900 & 1.090 & -4.089 & .289 \\
\hline \multirow{2}{*}{$\begin{array}{l}\text { Team } \\
\text { Behavior in } \\
\text { KS Post-test }\end{array}$} & $\begin{array}{l}\text { Equal variances } \\
\text { assumed }\end{array}$ & .756 & .396 & -1.902 & 18 & .073 & -1.900 & .999 & -3.999 & .199 \\
\hline & $\begin{array}{l}\text { Equal variances } \\
\text { not assumed }\end{array}$ & & & -1.902 & 17.485 & .074 & -1.900 & .999 & -4.003 & .203 \\
\hline
\end{tabular}

Similarly, the difference in team behavior post-test between the experimental group that played DGVSE ( $M$ $=23.63, S D=2.03)$ and the control group that played DGVNSE $(M=21.73, S D=2.42)$ was not statistically significant, $t(18)=-1.902, p=.073, d=.85$. $(p>.05)$. Therefore, there was insufficient evidence to reject the null hypothesis that there is no difference in pre- and post-team behavior in KS between team members who play DGVSE and team members who play DGVNSE at 275 minutes. The between-group effect size post-test, $d=.85$ was large. The $95 \%$ confidence interval for the difference in means ranged from $-3,998$ to .199 . The assumption of homogeneity of variance was evaluated using Levene's test and was not statistically significant $(p=.393)$. Equal variances across the groups and for the independent samples t-test to show mean differences in individual and team behavior in KS between the groups is verified in Table $\mathbf{2}$.

The application delivery, including setting up the server and running tests, was completed in less than five hours. Subsequently, confidence was adequately high to validate the feasibility assumption of delivery. During the $\mathbf{2 7 5}$ minutes of the program, there were six requests for additional training support (one participant from the control group and five from the experimental group), indicating that the confidence was adequately high to validate the feasibility assumption of time for additional learners' support. High fixed costs (including the cost of developing the games and the cost of purchasing the tablets to be used in the test) were US\$280,580, whereas the US\$382 variable costs (including operating costs, i.e., trainer costs) for 60 participants were very low. Trainers agreed to low pay in exchange for identity development as facilitators and to link their training practice with contemporary learning theories. Opportunity costs for 60 participants were US\$11,475. The cost of offering the KS program was US\$292,437. There might be value in separating one-time costs from the recurring costs incurred using a digital game in KS training of participants.

The cost to deliver the training program was greater than the assumed budget of no more than US\$150,000, indicating that the confidence level is inadequate to validate the feasibility assumption of the cost of delivering the training program. The cost was not in line with the estimated budget because of high revision costs resulting from sub-par game development in alignment with the game's purpose. Game designers had the challenge of adding or removing features that did not align with the game's instructional purpose under constraints, including working with remote game development teams under time restrictions. Stakeholders may face TEL with a high price tag that may or may not offer a clear benefit for the user. Educational researchers must validate assumptions about TEL before investing further significant amounts of resources in its development and potentially passing on high costs to users.

The sample size and participants' comments about the training program were an indication of whether the acceptability assumption of the training program was valid. The recruitment rate, indicated by sample size, was low. Forty-two percent (less than the $79 \%$ pre-established criterion) of the asked population was willing to volunteer to try out the novel and untested training program, indicating that the confidence was not 
adequate to validate the acceptability assumption of participant recruitment. There was a zero dropout rate (less than the $5 \%$ pre-established criterion) across the training program, with all participants completing the instruction and follow-ups, indicating that the confidence is adequate to validate the acceptability assumption of participant satisfaction.

\section{IMPLICATIONS OF RESULTS}

Researchers must eliminate activities representing costs that do not add value (Vas de Carvalho et al., 2014) from the prototype until its completion. Evident from the research findings, the absence of an iterative approach to the development of the digital games contributed to the infeasibility and ineffectiveness of the training program's outcome measures. The assumption validation process is a potent process that can assist educational researchers to focus on activities that aid in building the purpose of TEL from the early to the final stages of its development. By learning early from experimentation using empirical customer data, educational researchers can re-purpose what developers have built to satisfy stakeholders' needs promptly and avoid incurring costs that do not contribute to the value of TEL.

Educational researchers must develop explicit assumptions for each prototype and develop plans to test each assumption. In our illustrative example, we had done this quite thoroughly for our feasibility and acceptability assumptions but had not adequately identified the assumptions underlying our effectiveness assumption. The lack of statistical significance in the change in KS after team members played the digital game indicated the likely need for educational researchers to revise the digital game after conducting the pilot trial. The lack of significant statistical difference in the KS score, pre- and post- trial requires further investigation in assumptions and the digital game's redesign.

We have now identified a long list of assumptions that would have needed to be valid for the program to be appropriately assessed as effective. Reasons for the lack of statistical significance in KS learning from the game might have been the result of assumptions about the important influence of self-efficacy or self-efficacy for teamwork on KS, the usefulness of digital games as a training tool, or the instructional quality of the specific games. Other reasons for the lack of statistically significant results may be how the test was conducted and/or the appropriateness of the specific questionnaire used to measure KS learning. While it was the most relevant available questionnaire, it lacked reported quantitative reliability and validity testing. Additionally, the questionnaire was based on self-report data, which are reliant on participants' honest responses. Responses may contain certain limitations because of pre-existing opinions, biased recollections of recent events, or misrepresentation to please the researcher. Self-report bias can threaten an experiment's internal validity because participants tend to report in a manner that portrays them favorably (Donaldson \& Grant-Vallone, 2002).

Another unidentified assumption was the assumption that short-duration teams could be used to test the training program's effectiveness. Short-term, intense learning programs can positively influence academic self-efficacy and even reduce learners' attrition if experienced teachers conduct them in small groups (Walter et al., 2015). However, participants in this study may not have spent the time needed to get to know each other well enough to have become a cohesive team, thereby decreasing the influence of team efficacy on KS results. Antecedents for team cohesion are emotional intelligence and team member self-efficacy (Black et al., 2019).

Although the random assignment of participants to teams, and teams to experimental and control groups was intended to control for possible extraneous variables, it was likely that factors other than the experimental manipulation were responsible for any differences in KS over the 275 minutes of training. For example, prior digital game experience may have affected a participant's performance. Although the trial was methodologically rigorous, outliers must be addressed by setting up rules a priori for their exclusion; thereby, ensuring the data analysis is not adversely skewed. The data collected, however, are likely to hold some transferable potential. A recommendation is to use the Mann-Whitney $\mathrm{U}$ test, which does not require the assumption of normal distribution instead of the t-test. 
The newly developed digital games were based on the effectiveness assumption that included the untested, sequential relational proposition that a person's self-efficacy for teamwork is likely to lead to an increase in team efficacy, and an increase in team efficacy is likely to increase individual team member's self-efficacy regarding KS in teamwork and team members' engagement in KS. The game development also required consideration of pedagogically-driven dimensions that underpin learning design, including learner profiling (the divide between digital and non-digital natives); learning context (training space and an atmosphere conducive to learning); selection of pedagogies (the teamwork efficacy learning framework), and mode of representation (game concept, game engine, mode of deployment, and level of interactivity). Educational researchers can use this preliminary evidence as a guide when seeking to validate assumptions for training programs within educational contexts.

\section{LIMITATIONS OF THE ASSUMPTION VALIDATION PROCESS}

We have outlined an assumption validation process for the testing of TEL and included a recommendation to evolve prototypes. We developed the process because of the absence of an assessment approach that involves the specific activities necessary for educational researchers to evaluate the assumptions underlying TEL. We note as a limitation that the assumption validation process that we presented meets researchers' minimal needs in that only some assessment activities (effectiveness, feasibility, and acceptability) were proposed. The analysis of preliminary data and the preparation of assessment reports are also essential steps to consider when and if assumptions alter or change after a prototype's creation. Further, it would be impractical for any single assessment to collect all requisite information on an initiative incorporating TEL or for any single audience to find this information equally valuable. We also acknowledge that educational researchers have not yet substantially tested the assumption validation process in practice; nevertheless, it is a potentially powerful process, which may be adapted to differing contexts to help educational researchers evolve prototypes of TEL in a de-risked way in alignment with stakeholders' needs. We trust that other experienced appraisers will define their appraisal recipe by identifying their assumptions, assessment activities, and particular aspects of profound interest and applicability to their target audience and context.

\section{RECOMMENDATIONS}

Methods are frequently appraised in educational research and are not inherently 'good' or 'bad.' Concern lies in exposing the assumptions underlying methods and questioning the extent to which evidence supports the findings. Educational researchers should consider utilizing the assumption validation process introduced in this article when evolving ideas or prototypes. To illustrate the proposed process, a preliminary study of a specific application of TEL-a KS training program using digital games-is provided. The training program involved activities related to the teaching and learning of KS in organizations.

The utilization of an assumption validation process is necessary to prevent erroneous decision making about the progress of TEL and requires attention to appropriate statistical tests, validated measurement tools, learning objectives, learner-related variables, learning context, available resources, and consideration of additional dynamic elements that improve learners' educational experience including learners' perceptions and behavior. Educators as designers of TEL must not regard the design process as a single phase of the TEL's development, but as a cyclical process of refinement (Persico et al., 2018). The assumption validation process is a critical and potentially recurring step in the development process of TEL, and it is recommended to commence with the prototype (see Figure 1).

\section{CONCLUSION}

Technology-enhanced learning encompasses a complex system of technological, educational, and social change (Bayne, 2015). Studies involving TEL are intricate and demand best practices for their systematic assessment so that researchers understand the components and search for ways to replicate the results (Pauline-Graf \& Mandel, 2019). Educational researchers can maximize the possibilities of TEL by being fully prepared to expect both favorable and unfavorable results regarding the effectiveness, feasibility, and 
acceptability of its outcome measures. Even non-significant results can help them implement strategies to understand which parts of an initiative that incorporates TEL work and which parts do not by addressing each of the dimensions that inform learning, separately and in combination, and tweaking administrative processes to seek results that can be projected to a larger group before investing resources in a full-scale study.

In line with this paper's objective to inform the research question, "How can educational researchers identify, reveal, and validate critical assumptions about TEL early and often in its course of development and implementation?", an assumption validation process was introduced for educational researchers to consider utilizing when evolving ideas or prototypes. Educational researchers can use this process to make quick, informed, de-risked decisions about the progress of prototypes of TEL. Educational researchers in the expanding fields of educational technology can review this assumption validation process as a guide to conducting preliminary studies. They can discuss prior approaches to similar-type studies; more easily share ideas for best scientific practice across subject areas; and contribute to the published literature as the value of theory and practice continues to be developed.

\footnotetext{
Author contributions: All authors were involved in concept, design, collection of data, interpretation, writing, and critically revising the article. All authors approve final version of the article.

Funding: Pilot trials were funded by Novomatic AG.

Acknowledgements: This article is a culmination of the research and shared experiences with my co-authors, who have contributed to my education in management. I value the support from Bartlomiej Czapkiewicz and Maria Staudacher from Novomatic AG for the training program's facilitation. From Octavian Game Art Ltd., I am proud to work with Dmitriy Fedorov, who improved the artistic aspects of the game, and am thankful to the management and volunteers at Octavian.SPb.Ltd. for their tireless efforts and active participation in the training program's rollout strategy.

Declaration of interest: Authors declare no competing interest.

Disclosure statement: Whereas Novomatic AG funded the pilot trial, including developing and testing the game versions, the study belongs to the principal researcher. If the digital games were successful, the use of digital games for experiential learning in organizations might be a natural future opportunity for Novomatic, even though Novomatic is not currently in the business of developing or selling digital games for experiential learning.

Data availability: Data generated or analysed during this study are available from the corresponding author on request.
}

\section{REFERENCES}

Al-Azawi, R., Al-Faliti, F., \& Al-Blushi, M. (2016). Educational gamification vs. game based learning: Comparative study. International Journal of Innovation, Management and Technology, 7(4), 132-136. https://doi.org/10.18178/ijimt.2016.7.4.659

Apiola, M., Lokkila, E., \& Laakso, M.-J. (2019). Digital learning approaches in an intermediate-level computer science course. International Journal of Information \& Learning Technology, 36(5), 467-484. https://doi.org/10.1108/IJILT-06-2018-0079

Arnold, D., Burns, K., Adhikari, N., Kho, M., Meade, M., \& Cooke, D. (2009). The design and interpretation of pilot trials in clinical research in critical care. Critical Care Medicine, 37(1 Suppl), 69-74. https://doi.org/10.1097/CCM.0b013e3181920e33

Baack, D., Dow, D., Parente, R., \& Bacon, D. (2015). Confirmation bias in individual-level perceptions of distance: An experimental investigation. Journal of International Business Studies, 46(8), 938-959. https://doi.org/10.1057/jibs.2015.19

Bandura, A. (1977). Self-efficacy: Toward a unifying theory of behavioral change. Psychological Review, 84(2), 191-215. https://doi.org/10.1037/0033-295X.84.2.191

Bartolomé, A., Castañeda, L., \& Adell, J. (2018). Personalisation in educational technology: The absence of underlying pedagogies. International Journal of Educational Technology in Higher Education, 15(14), 117. https://doi.org/10.1186/s41239-018-0095-0 
Bayne, S. (2015). What's the matter with 'technology enhanced learning'? Learning, Media and Technology, 40(1), 5-20. https://doi.org/10.1080/17439884.2014.915851

Beckstead, J. (2013). On measurements and their quality: Paper 2: Random measurement error and the power of statistical tests. International Journal of Nursing Studies, 50(10), 1416-1422. https://doi.org/10.1016/j.ijnurstu.2013.04.010

Bennett, S., \& Oliver, M. (2011). Talking back to theory: The missed opportunities in learning technology research. Research in Learning Technology, 19(3), 179-189. https://doi.org/10.3402/rlt.v19i3.17108

Black, J., Kim, K., Rhee, S., Wang, K., \& Sakchutchawan, S. (2019). Self-efficacy and emotional intelligence: Influencing team cohesion to enhance team performance. Team Performance Management: An International Journal, 25(1/2), 100-119. https://doi.org/10.1108/TPM-01-2018-0005

Chen, M.-L., \& Lin, C.-P. (2013). Assessing the effects of cultural intelligence on team knowledge sharing from a socio-cognitive perspective. Human Resource Management, 52(5), 675-695. https://doi.org/10.1002/hrm.21558

Cook, D., \& Ellaway, R. (2015). Evaluating technology-enhanced learning: a comprehensive framework. Medical Teacher, 37(10), 961-970. https://doi.org/10.3109/0142159X.2015.1009024

Courtright, S., Colbert, A., \& Choi, D. (2014). Fired up or burned out? How developmental challenge differentially impacts leader behavior. Journal of Applied Psychology, 99(4), 681-696. https://doi.org/10.1037/a0035790

Cózar-Gutiérrez, R., \& Sáez-López, J. (2016). Game-based learning and gamification in initial teaching training in social sciences: an experiment with MinecraftEdu. International journal of Educational technology in Higher Education, 13(1), 2. https://doi.org/10.1186/s41239-016-0003-4

Crook, C., \& Gu, X. (2019). How new technology is addressed by researchers in educational studies: Approaches from high-performing universities in China and the UK. British Journal of Educational Technology, 50(3), 1173-1188. https://doi.org/10.1111/bjet.12750

Donaldson, S., \& Grant-Vallone, E. (2002). Understanding self-report bias in organizational behavior research. Journal of Business and Psychology, 17(2), 245-260. https://doi.org/10.1023/A:1019637632584

Ellaway, R. (2014). Virtual patients as activities: Exploring the research implications of an activity theoretical stance. Perspectives on Medical Education 3(4), 266-277. https://doi.org/10.1007/s40037-014-0134-z

Ellaway, R., Pusic, M., Gailbraith, R., \& Cameron, T. (2014a). Developing the role of big data and analytics in health professional education. Medical Teaching, 36(3), 216-222. https://doi.org/10.3109/0142159X.2014.874553

Ellaway, R., Pusic, M., Yavner, S., \& Kalet, A. (2014b, March 9). Context matters. Emergent variability in an effectiveness trial of online teaching modules. Medical Education, 48(4), 386-396. https://doi.org/10.1111/medu.12389

Filippova, T. (2015). Priority fields of e-learning development in Russia. Procedia - Social and Behavioral Sciences, 206, 348-353. https://doi.org/10.1016/j.sbspro.2015.10.063

Frye, W., \& Hemmer, P. (2012). Program evaluation models and related theories: AME guide no. 67. Medical Teacher, 34(5) e288-e299. https://doi.org/10.3109/0142159X.2012.668637

Giannakas, F., Kambourakis, G., Papaslouros, A., \& Gritzalis, S. (2018). A critical review of 13 years of mobile game-based learning. Educational Technology Research and Development, 66(2), 341-384.

Goodyear, P., \& Retalis, S. (2010). Learning, technology and design. In P. Goodyear \& S. Retalis (Eds.), Technology-enhanced learning: Design patterns and pattern languages (pp. 1-28). Sense Publishers. 
Gresalfi, M., \& Barnes, J. (2016). Designing feedback in an immersive videogame: supporting mathematical engagement. Educational Technology Research and Development, 64(1), 65-86. https://doi.org/10.1007/s11423-015-9411-8

Hagemeier, N., Hess, R., Hagen, K., \& Sorah, E. (2014). Impact of an interprofessional communication course on nursing, medical, and pharmacy students' communication skill self-efficacy beliefs. American Journal of Pharmaceutical Education, 78(10), 186-196. https://doi.org/10.5688/ajpe7810186

Harvey, J. (1998). Evaluation cookbook. Edinburgh: Learning Technology Dissemination Initiative. Heriot-Watt University, Edinburgh.

Hussein, M., Ow, S., Cheong, L., Thing, M., \& Ebrahim, N. (2019). Effects of digital game-based learning on elementary science learning: A systematic review. IEEE Access, 7, 62465-62478. https://doi.org/10.1109/ACCESS.2019.2916324

Hwa, S. (2018). Pedagogical change in mathematics learning: Harnessing the power of digital game-based learning. Journal of Educational Technology \& Society, 21(4), 259-276.

Khan, A., Ahmad, F., \& Malik, M. (2017). Use of digital game based learning and gamification in secondary school science: The effect on student engagement, learning and gender difference. Education and Information Technologies, 22(6), 2767-2804. https://doi.org/10.1007/s10639-017-9622-1

Kiili, K. (2005). Digital game-based learning: Towards an experiential gaming model. Internet and Higher Education, 8(1), 13-24. https://doi.org/10.1016/j.iheduc.2004.12.001

Kirkwood, A., \& Price, L. (2013). Examining some assumptions and limitations of research on the effects of emerging technologies for teaching and learning in higher education. British Journal of Educational Technology, 44(4), 536-543. https://doi.org/10.111/bjet.12049

Kirkwood, A., \& Price, L. (2014). Technology-enhanced learning and teaching in higher education: what is 'enhanced' and how do we know? A critical literature review. Learning, Media and Technology, 39(1), 6-36. https://doi.org/10.1080/17439884.2013.770404

Koh, C., Tan, H., Tan, K., Fang, L., \& Fong, F., Kan, D., Lye, S., \& Wee, M. (2010). Investigating the effect of 3D simulation-based learning on the motivation and performance of engineering students. Journal of Engineering Education, 99(3), 237-251. https://doi.org/10.1002/j.2168-9830.2010.tb01059.x

Kurvinen, E., Kaila, E., Laakso, M.-J., \& Salakoski, T. (2020). Long term effects on technology enhanced learning: The use of weekly digital lessons in Mathematics. Informatics in Education, 19(1), 51-75. https://doi.org/10.15388/infedu.2020.04

Larionova, V., Brown, K., Bystrova, T., \& Sinitsyn, E. (2018). Russian perspectives of online learning technologies in higher education: An empirical study of a MOOC. Research in Comparative \& International Education, 13(1), 70-91. https://doi.org/10.1177/1745499918763420

Lee, Y-H. (2015). Does digital game interactivity always promote self-efficacy? Cyberpsychology, Behavior, and Social Networking, 18(11), 669-673. https://doi.org/10.1089/cyber.2015.0165

Li, Z., Cheng, Y., \& Liu, C. (2013). A constructionism framework for designing game-like learning systems: Its effect on different learners. British Journal of Educational Technology, 44(2), 208-224. https://doi.org/10.1111/j.1467-8535.2012.01305.x

Liu, Z.-Y., Shaikh, Z., \& Gazizova, F. (2020). Using the concept of game-based learning in education. International Journal of Emerging Technologies in Learning, 15(14), 53-64. https://doi.org/10.39991/ijet.v15i14.14675 
Niederhauser, D., Howard, S., Voogt, J., Agyei, D., Laferriere, T., Tondeaur, J., \& Cox, M. (2018). Sustainability and scalability in educational technology initiatives: Research-informed practice. Technology, Knowledge and Learning, 23(3), 507-523. https://doi.org/10.1007/s10758-018-9382-z

Ojedokun, O., \& Idemudia, E. (2014). Examining the roles of gender and personal dispositions in attitudes toward knowledge sharing of senior administrators. Gender \& Behaviour, 12(3), 5857-5867.

Oliver, E. (2018). Digital game-based learning and technology-enhanced learning for theological education. Verbum et Ecclesia, 39, 1-8. https://doi.org/10.4102/ve.v39i1.1900

Oliver, M. (2011). Technological determinism in educational technology research: some alternative ways of thinking about the relationship between learning and technology. Journal of Computer Assisted Learning, 27(5), 373-384. https://doi.org/10.111/j1365-2729.2011.00406.x

Olowodunoye, S. (2015). Knowledge sharing behavior: The role of self-efficacy, organizational justice and organizational tenure. European Scientific Journal, 11(17), 254-264.

Osman, S., Sauid, M., \& Azizan, N. (2015). Knowledge sharing patterns among undergraduate students in Universiti Teknologi MARA (UiTM) Johor, Malaysia. International Journal of Management, Accounting and Economics, 2(3), 167-178.

Passey, D. (2019). Technology-enhanced learning: Rethinking the term, the concept, and its theoretical background. British Journal of Educational Technology, 50(3), 972-986. https://doi.org/10.1111/bjet.12783

Pauline-Graf, D., \& Mandel, S. E. (2019). Defining preliminary research for digital game-based learning evaluation: Best practices. International Journal of Educational Methodology, 5(4), 623-635. https://doi.org/10.12973/ijem.5.4.623

Persico, D., Pozzi, F., \& Goodyear, P. (2018). Teachers as designers of TEL programs. British Journal of Educational Technology, 49(6). https://doi.org/10.1111/bjet.12706

Pickering, J., Lazarus, M., \& Hallam, J. (2019). A practitioner's guide to performing a holistic evaluation of technology-enhanced learning in medical education. Medical Science Educator, 29(4), 1095-1102. https://doi.org/10.1007/s40670-019-00781-7

Prosser, M., Trigwell, K., \& Taylor, P. (1994). A phenomenographic study of academics' conceptions of science learning and teaching. Learning and Instruction, 4(3), 217-232. https://doi.org/10.1016/09594752(94)90024-8

Qian, M., \& Clark, K. (2016). Game-based learning and $21^{\text {st }}$ century skills: A review of recent research. Computers in Human Behavior, 63, 50-58. https://doi.org/10.1016/j.chb.2016.05.023

Samuelowicz, K., \& Bain, J. (1992). Conceptions of teaching held by academic teachers. Higher Education, 24(1), 93-111. https://doi.org/10.1007/BF00138620

Sanders, J. (2012). Technology-enhanced learning. Education for Primary Care, 23(3), 228-229. https://doi.org/10.1080/14739879.2012.11494107

Shaari, R., Rahman, S., \& Rajab, A. (2014). Self-efficacy as a determined factor for knowledge sharing awareness. International Journal of Trade Economics and Finance, 5(1), 39-42. https://doi.org/10.7763/IJTEF.2014.V5.337

Shahriarpour, N., \& Kafi, Z. (2014). On the effect of playing digital games on Iranian intermediate EFL learners' motivation toward learning English vocabularies. Procedia - Social and Behavioral Sciences, 98, 17381734. https://doi.org/10.1016/j.sbspro.2014.03.601 
Shao, Z., Wang, T., \& Feng, Y. (2015). Impact of organizational culture and computer self-efficacy on knowledge sharing. Industrial Management \& Data Systems, 115(4), 590-611. https://doi.org/10.1108/IMDS-12-2014-0377

Swinkels, M., Koopman, M., \& Beijaard, D. (2013). Student teachers' development of learning focused conceptions. Teaching and Teacher Education, 34, 26-37. https://doi.org/10.1016/j.tate.2013.03.003

Tang, S., Hanneghan, M., \& Carter, C. (2013). A platform independent game technology model for model driven serious game development. The Electronic Journal of e-Learning, 11(1), 61-79.

Tasa, K., Taggar, S., \& Seijts, G. (2007). The development of collective self-efficacy in teams: A multilevel and longitudinal perspective. Journal of Applied Psychology, 92(1), 17-27. https://doi.org/10.1037/00219010.92.1.17

Van Driel, J., \& Berry, A. (2012). Teacher professional development focusing on pedagogical content knowledge. Educational Researcher, 41(1), 26-28. https://doi.org/10.3102/0013189X11431010

Vas de Carvalho, C., Lopes, M., \& Ramos, A. (2014). Lean games approaches - Simulation games and digital serious games. International Journal of Advanced Corporate Learning, 7(1), 11-16. https://doi.org/10.3991/ijac.v7il.3433

Van Genderen, E. (2014). Strategic knowledge sharing: Culture acting as an inhibitor. Middle East Journal of Business, 9(4), 3-8.

Vetushinskiy, A., \& Zhukov, P. (2019). Gamification of school education in Russia: Case study. In J. ArnedoMoreno, C. S. González, \& A. Mora (Eds.), Proceedings of the 3rd International Symposium on Gamification and Games for Learning (GamiLearn'19), Barcelona, Spain. http://ceur-ws.org

Walter, O., Shenaar-Golan, V., \& Greenberg, Z. (2015). Effect of short-term program on academic self-efficacy in higher education. Psychology, 6(10), 1199-1215. https://doi.org/10.4236/psych.2015.610118

Zawadzki, M., Danube, C., \& Shields, S. (2012). How to talk about gender inequity in the workplace: Using WAGES as an experiential learning tool to reduce reactance and promote self-efficacy. Sex Roles, 67(11-12), 605-616. https://doi.org/10.1007/s11199-012-0181-z

Correspondence: Denise Pauline-Graf, Novomatic AG, Austria and University of Phoenix, Phoenix, AZ, USA. E-mail: Dpauline-graf@novomatic.com 


\section{APPENDIX 1}

\section{Game Description}

Self-efficacy theory for teamwork was the core constituent underpinning the knowledge sharing (KS) training program, which was a one-week training intervention that involved two versions of a digital game. The game was divided into two phases: Player character (PC) selection and document elimination. PC selection involved team members having to assume one of the three roles by selecting a PC (Rita the cleaner, Herbert the technician, or the Manager) under time pressure. Although the Manager was a nameless PC to provoke a sense of superiority, his abilities were weaker than the other two PCs (see Figure 2).

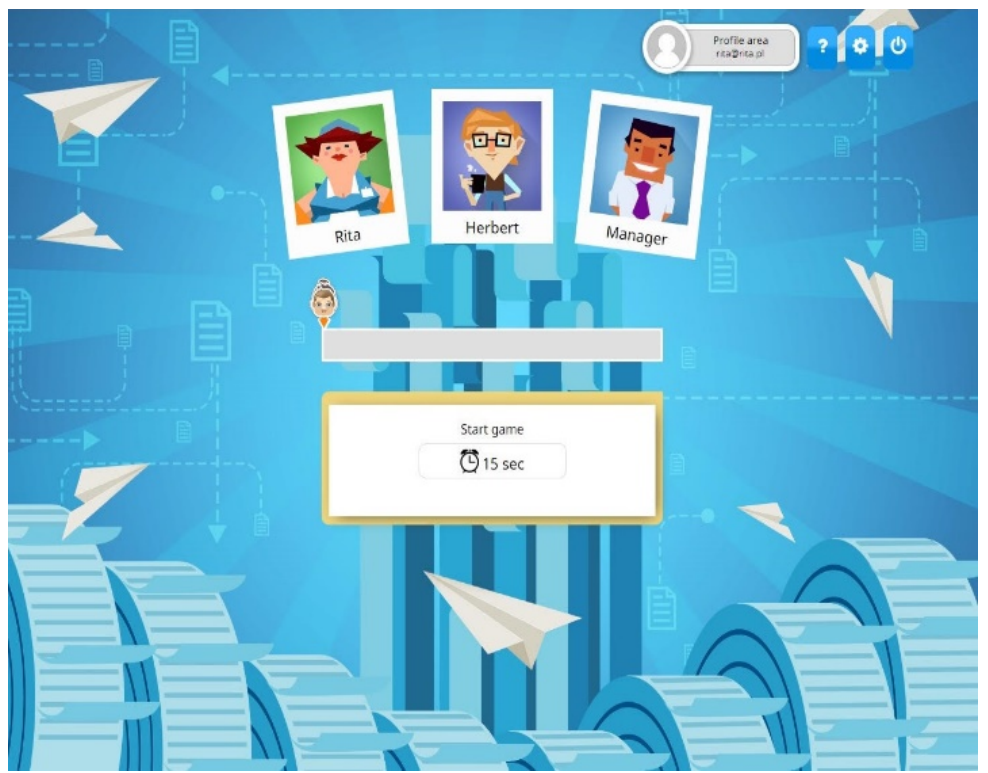

Figure 2. Image taken of phase 1 of the game - PC selection under time pressure

Document elimination involved each team member removing documents that storm the game field by using the abilities unique to their PC and to the selected PCs of the members of their team. Game objects were also present in phase 2 of the game that could either contribute to or detract from the PCs' moving speed to eliminate documents. A win-lose situation in the game did not exist; rather the game used mechanics that required team members to recognize the unique abilities of their team and develop their self-efficacy for teamwork to process the influx of documents the fastest. The number of documents processed by each team was reflected in the final score of each game exercise (see Figure 3 ).

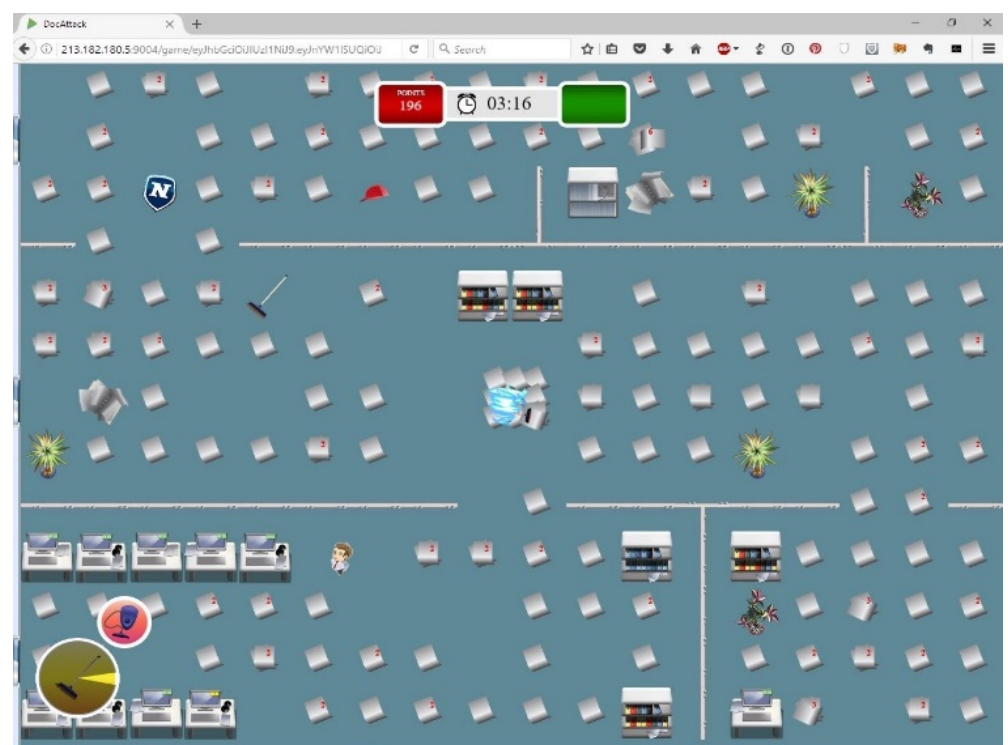

Figure 3. Image taken of phase 2 of the game - document elimination 
Team scores for both groups were calculated and updated continuously during game sessions. The server recorded daily the game session's end times and the final scores for each team. A rise in team scores during the week for each game version would be an indication of the quality of the games and whether self-efficacy for teamwork and subsequently team efficacy, was growing throughout the week. Each team's scores was displayed on-screen in real-time, which the other teams could track. Higher team scores for the intervention group compared with the control group was an indication that DGVSE did contain self-efficacy components. 